\title{
Growth hormone status predicts left ventricular mass in patients after cure of acromegaly
}

\section{Citation}

Wexler, Tamara L., Ronen Durst, David McCarty, Michael H. Picard, Lindsay Gunnell, Zehra Omer, Pouneh Fazeli, Karen K. Miller, and Anne Klibanski. 2010. "Growth Hormone Status Predicts Left Ventricular Mass in Patients after Cure of Acromegaly." Growth Hormone \& IGF Research 20 (5) (October): 333-337. doi:10.1016/j.ghir.2010.05.003.

\section{Published Version}

doi:10.1016/j.ghir.2010.05.003

\section{Permanent link}

http://nrs.harvard.edu/urn-3:HUL.InstRepos:29048913

\section{Terms of Use}

This article was downloaded from Harvard University's DASH repository, and is made available under the terms and conditions applicable to Other Posted Material, as set forth at http:// nrs.harvard.edu/urn-3:HUL.InstRepos:dash.current.terms-of-use\#LAA

\section{Share Your Story}

The Harvard community has made this article openly available.

Please share how this access benefits you. Submit a story.

\section{Accessibility}




\title{
Growth hormone status predicts left ventricular mass in patients after cure of acromegaly
}

\author{
Tamara L. Wexlera, Ronen Durst ${ }^{\mathrm{b}}$, David McCarty ${ }^{\mathrm{b}}$, Michael H. Picard ${ }^{\mathrm{b}}$, Lindsay Gunnella, \\ Zehra Omera , Pouneh Fazelia, Karen K. Millera, and Anne Klibanski ${ }^{a}{ }^{\text {, }}$ \\ aNeuroendocrine Unit, Massachusetts General Hospital and Harvard Medical School, Boston, \\ MA, 02114, United States \\ bDivision of Cardiology, Massachusetts General Hospital and Harvard Medical School, Boston, \\ MA, 02114, United States
}

\begin{abstract}
Context-Growth hormone excess and growth hormone deficiency (GHD) are both associated with increased cardiovascular morbidity. A specific acromegaly-related cardiomyopathy has been described, characterized in part by increased left ventricular mass (LVM). Growth hormone deficiency is associated with reduced LVM. Following cure of acromegaly with surgery or radiation therapy, GHD may develop; however, its effects on cardiac morphology and function in this population are not established.
\end{abstract}

Objective-We hypothesized that the development of GHD in patients with prior acromegaly would be associated with cardiacmorphologic and functional changes that differ from those in patients who are GH sufficient following cure of acromegaly.

Design-A cross-sectional study was conducted in a Clinical Research Center. Study participants consisted of three groups of subjects ( $n=34)$ : I. Cured acromegaly with GHD ( $n=15)$, II. Cured acromegaly with GH sufficiency $(n=8)$, and III. Active acromegaly $(n=11)$. Main outcome measures included cardiac morphology and function, using echocardiography parameters.

Results-Mean age and BMI, $44.6 \pm 2.3$ years (SEM) and $30.7 \pm 1.3 \mathrm{~kg} / \mathrm{m}^{2}$, respectively, were not different among the three groups. Mean peak GH values were: I. $2.8 \pm 0.4 \mathrm{ng} / \mathrm{ml} ; \mathrm{II}$. $30.1 \pm 9.1 \mathrm{ng} / \mathrm{ml}$ ( $p=0.0002$.) In group I, left ventricular mass, indexed to body surface area (LVMi), was within the normal range in all patients; moreover, left ventricular (LV) geometry was normal. At least 50\% of patients in groups II and III had elevated LVMi, and in 50\% of patients, LV geometry was abnormal, indicating pathologic hypertrophy. Ejection fraction was similar between all three groups. There were no significant differences in diastolic function.

Conclusions-Patients who develop GHD following cure of acromegaly do not demonstrate elevated LV mass, in contrast to patients with a history of acromegaly but normal GH levels or to patients with active acromegaly. This suggests that GH status after treatment of acromegaly correlates with LV mass, and that, in GH sufficient patients, reversal of remodeling may be slower than previously thought. These data suggest that it will be important to determine whether GH replacement alters left ventricular morphology over time.

\section{Keywords}

Acromegaly; Growth hormone deficiency; Left ventricular mass

(C) 2010 Growth Hormone Research Society. Published by Elsevier Ltd. All rights reserved.

*Corresponding author. Neuroendocrine Unit, Bulfinch 457B, Massachusetts General Hospital, Boston, MA 02114 . Tel.: +1 617 726 3870; fax: +1 617726 5072. AKlibanski@partners.org (A. Klibanski). 


\section{Introduction}

Cardiovascular (CV) disease is a leading cause of death in acromegaly. Overall survival is reduced by an average of ten years in active acromegaly [1], and persistent disease following surgical intervention carries a 2 to 3.5 -fold increased relative mortality risk per year [2-4]. The sequelae of growth hormone excess include structural and functional cardiac changes, as well as inflammatory and metabolic effects [5]. A distinct entity of cardiac hypertrophy associated with acromegaly has been described [6,7], independent of the hypertension often seen in these patients $[8,9]$. Morphological cardiac changes include increased left ventricular mass (LVM) [8,10-12], which appears to reflect interstitial fibrosis as well as increased myocyte size $[13,14]$. Increased stroke volume and cardiac output, and decreased endsystolic stress and systemic vascular resistance, have also been observed $[8,12]$. Structural changes may occur before any clinical signs of cardiac dysfunction [6]; left ventricular (LV) hypertrophy is seen even in younger patients with shorter durations of disease $[12,15]$.

Normalization of GH and/or IGF-1 levels reduces mortality rates to normal and is therefore a major therapeutic goal in the treatment of acromegaly $[1,3,4]$. Treatment, whether medical or surgical, has also been shown to reduce left ventricular mass index (LVMi) [8,10,16-19]. With transsphenoidal surgery, radiosurgery, and current medical therapy, the majority of patients with acromegaly can achieve biochemical control. However, patients may develop growth hormone deficiency (GHD) after curative surgery or radiation therapy.

GHD, in patients without a history of acromegaly, carries an increased risk of CV mortality [20], and is well-established to be associated with increased CV risk. This risk is characterized not only by metabolic effects [21-33] and systolic hypertension [22,31] but also by reduced LVM and LV systolic function, including decreased ejection fraction (EF) [34-37]. Growth hormone replacement has been demonstrated in such patients to increase the reduced LVMi and to improve EF [8,36,38]. However, in patients with GHD with a history of acromegaly, the implications for cardiovascular risk and cardiac function are largely unknown.

Although cure of acromegaly is associated with a reduction in the mortality attributable to GH excess [3], subsequent GHD may be a contributing factor to cardiovascular morbidity and mortality in this group of patients, as it is in patients with GHD due to other types of pituitary disease and treatment. We hypothesized that patients who develop GHD following treatment of acromegaly have cardiac morphologic differences compared to those patients who are GH sufficient. We therefore investigated the effects of GHD on cardiac morphology and function by echocardiography in patients with prior acromegaly, compared to patients who were GH sufficient after treatment of acromegaly and to those with active disease.

\section{Materials and methods}

\subsection{Study participants}

Two dimensional echocardiograms with Doppler were performed on 34 adults (ages 18-75) with histories of acromegaly, in the following groups: I. Cured acromegaly with growth hormone deficiency (GHD, $n=15$ ); II. Cured acromegaly with current growth hormone sufficiency (GHS, $n=8$ ); III. Active acromegaly (AA, $n=11$ ). Study participants were diagnosed with GHD based on a peak $\mathrm{GH}<5 \mathrm{ng} / \mathrm{ml}$ in response to GHRH-arginine stimulation, performed as previously described [39], or an IGF-1 level more than two standard deviations below the age-specific normal range in subjects with at least three other documented anterior pituitary hormone deficiencies [40]. Subjects receiving thyroid 
hormone, gonadal steroid and/or glucocorticoid replacement therapy were required to have received stable replacement doses for at least three months prior to entry into the study.

Exclusion criteria included pharmacologic treatment of acromegaly including somatostatin analogs, dopamine agonists or growth hormone receptor antagonists, untreated adrenal or thyroid deficiency, hemoglobin $<11.0 \mathrm{~g} / \mathrm{dl}$, ALT/AST $>3 \times$ the upper limit of normal, creatinine level $>2.5 \mathrm{mg} / \mathrm{dl}$, congestive heart failure (NewYork Heart Association's Classes II-IV) (unstable coronary artery or cerebrovascular disease), pregnancy, breastfeeding, uncontrolled diabetes (HbA1C>7.5, fasting glucose $>126 \mathrm{mg} / \mathrm{dl}$, or $2 \mathrm{~h}$ OGTT glucose $>200$ $\mathrm{mg} / \mathrm{dl}$ ), or known acute illness. The study was conducted in the Clinical Research Centers of the Massachusetts General Hospital (MGH) and Massachusetts Institute of Technology. The study was approved by the Partners Healthcare and Massachusetts Institute of Technology Institutional Review Boards, and all subjects gave written informed consent. Clinical characteristics on a subset of the study participants, but no echocardiographic studies, were previously reported [41].

\subsection{Echocardiography}

Echocardiographic images were acquired with a 2.5-5 MHz transducer on a Vivid-7 or Vivid-I cardiac ultrasound system (GE Healthcare, Milwaukee, Wisconsin) at the MGH Cardiac Ultrasound Laboratory. Offline analysis was performed using Echopac version BT08 (GE Healthcare, Milwaukee, Wisconsin). Standard transthoracic echocardiographic images were acquired from parasternal and apical windows with the patient in the left lateral semi-recumbent position. Parasternal long axis and short axis views of the left and right ventricle, and apical four chamber, two chamber and long axis views were recorded. Four cardiac cycles were recorded during each acquisition.

Left ventricular dimensions were measured according to the recommendations of the American Society of Echocardiography [42]. Relative wall thickness (RWT) was calculated as [( $2 \mathrm{X}$ posterior wall thickness)/LV end diastolic internal dimension)] [42]. LVM was calculated from LV dimensions using the Penn method [43]. LV volumes were measured from the apical four and two chamber views by the biplane method of discs. Left atrial volume (LAV) was measured using the area-length method. Where appropriate, lengths and volumes were corrected for body surface area. Pulsed wave Doppler was performed at the level of the mitral leaflet tips to obtain parameters of LV diastolic filling [peak early filling (E) and atrial contraction (A) velocities, E/A ratio, E wave deceleration time]. Spectral pulsed wave Doppler was performed to obtain tissue velocities at the lateral mitral annulus. The peak myocardial systolic $\left(\mathrm{S}^{\prime}\right)$, early $\left(\mathrm{E}^{\prime}\right)$, and late $\left(\mathrm{A}^{\prime}\right)$ diastolic velocities were measured, and the $\mathrm{E} / \mathrm{E}^{\prime}$ ratio calculated. These diastolic parameters were used to categorize LV diastolic function as normal or abnormal, with the grade of dysfunction determined according to the recommendations of the American Society of Echocardiography [44].

Normal values for LVM were based on prior published data from the Framingham heart study [42]. Normal range of LVM was defined as $\pm 2 \mathrm{SD}$ of the mean reference values corrected for gender. Patients were classified into one of three mutually exclusive patterns of pathological LV hypertrophy, based on the ratio of LVM to the RWT, as follows: concentric hypertrophy (increased LVM with increased RWT); eccentric hypertrophy (increased LVM with normal RWT); and concentric remodeling (normal LVM with increased RWT) [45].

\subsection{Biochemical analysis}

Serum and plasma samples were collected and stored at $-80{ }^{\circ} \mathrm{C}$. Serum IGF-I levels were measured by Immulite 2000 automated immunoanalyzer (Diagnostic Products Corp., Inc, 
Los Angeles, CA), a solid-phase, enzyme-labeled chemiluminescent immunometric assay with an inter-assay coefficient of variation of $3.7 \%-4.2 \%$.

\subsection{Statistical analysis}

JMP Statistical Discoveries software (version 4.0.2; SAS Institute, Inc., Cary, NC) was used for statistical analysis. All variables were tested for normality using the Shapiro-Wilk test. Means were compared with ANOVA for normally distributed variables. For non-normally distributed variables, nonparametric comparisons were performed using the Wilcoxon test. Univariate regression models were constructed to determine whether change in IGF-1 levels predicted changes in the endpoints studied. Statistical significance was defined as a 2-tailed $p$ value less than 0.05 . Baseline characteristics (Table 1) are expressed as mean \pm SD and results are expressed as mean \pm SEM unless otherwise noted. Echocardiographic measurements were indexed by body surface area where indicated.

\section{Results}

\subsection{Clinical characteristics (Table 1)}

Clinical characteristics, including etiology of hypothalamic/pituitary disease and characterization of pituitary hormone deficiencies, are shown in Table 1. Age and gender distributions were comparable in the three groups (I: GHD post-acromegaly; II: GHS postacromegaly; III: active acromegaly.) Mean age was $44.6 \pm 2.3$ years (SEM). In all but one subject in Groups I and II, diagnosis of GHD or GH sufficiency was based on GH stimulation testing as described above, and not according to IGF-1 level. Mean peak GH values were significantly lower in Group I $(2.8 \pm 0.4 \mathrm{ng} / \mathrm{ml})$ than in Group II $(30.1 \pm 9.1 \mathrm{ng}$ / $\mathrm{ml})(p=0.0002$.) As expected, IGF-1 levels were higher in the active acromegaly group (III) than the treated groups (I, II). Active disease in Group III was defined by an IGF-1 level more than 1.5 times the upper limit of normal. Central hypothyroidism was present only in subjects in groups I and II, but all patients were replaced to euthyroid range, and there was no significant difference in mean free T4 values among all three groups. BMI did not differ significantly between the groups (mean BMI $30.7 \pm 1.3 \mathrm{~kg} / \mathrm{m}^{2}$ ). There were no significant differences between the groups in systolic blood pressure, diastolic blood pressure or mean arterial pressure. There was no difference in time since surgery among groups, or in time since radiotherapy between Groups I and II (See Table 1).

\subsection{Echocardiographic findings}

3.2.1. Left ventricular mass index-Left ventricular mass index (LVMi) correlated significantly with IGF-1 levels ( $R$ value $0.37, p=0.037$ ), and there was a trend towards an association with peak GH $(R$ value $0.42, p=0.066$.) LVMi was also associated with systolic blood pressure $(R=0.53, p=0.005)$, and there was a trend toward an association with mean arterial pressure $(R=0.33, p=0.089)$. GH deficient patients had significantly lower LVMi compared to the two other groups (Fig. 1). Mean LVMi values by group were: I. 86.2 \pm 4.6 ; II. 108.4 \pm 8.9 ; and III. $105.7 \pm 8.9 \mathrm{~g} / \mathrm{BSA}$. As seen in Table $2,62 \%$ of GHS and $45 \%$ of AA patients (groups II and III) had elevated LVMi, while all GHD patients (group I) had LVM measurements in the normal range.

Seventy-seven percent of GHD patients (Group I) had normal LV mass, and 23\% had concentric hypertrophy. In the GHS group (II), 50\% of subjects had normal LV mass, $16 \%$ had eccentric hypertrophy and 33\% had concentric hypertrophy. In the AA group (III), 50\% had normal LV mass and 50\% of subjects had concentric hypertrophy.

There was no significant correlation between LVMi and the following variables: time since acromegaly treatment (surgery or radiotherapy), duration of acromegaly symptoms prior to 
treatment, age, or diastolic blood pressure. Mean LVMi did not differ between subjects receiving and not receiving antihypertensive medications.

\subsection{LVEDV, EF, LAV, E/A, aortic root}

Ejection fraction was similar among all groups, with mean EF of $63 \pm 1 \%$, and no significant difference was observed in indexed LAV or aortic root diameter. Diastolic dysfunction was equally distributed among the 3 groups (Table 3 ).

\section{Discussion}

Hypopituitarism confers an increased risk of cardiovascular events and death in patients with GHD resulting from treatment of non-somatotroph pituitary disease. It has been proposed that GHD is an important factor. Such patients are routinely treated with GH replacement. However, patients treated for acromegaly have typically not been screened for GHD, and if GHD is diagnosed it is not uniformly treated. While cardiovascular sequelae of acromegaly and the mortality benefit of biochemical cure are well-established [3], it is unknown whether the GH deficiency state that may follow definitive therapy introduces additional cardiovascular risk or cardiac dysfunction.

In this study we show that subjects with GHD after successful definitive treatment of acromegaly have lower LVMi measurements than both GH sufficient subjects and those with active acromegaly. The GH deficient subjects' LVMi measurements are in the lower normal range, and the majority have normal LV geometry; these LVMi measurements are consistent with literature reports of reduced LVM in GHD patients [36]. In contrast, subjects who are GH sufficient after successful acromegaly treatment demonstrate increased LVM (with $62 \%$ having measurements above the upper limit of normal) and pathologic remodeling. Subjects with active acromegaly have increased LVM and abnormal LV geometry, as has been well-established. Given that all three groups studied were of similar age and BMI, and none had untreated hypertension, differences in past exposure to GH and current levels of GH secretion were likely important determinants of left ventricular mass index.

The finding of significant LV hypertrophy not only in patients with GH excess (Group III) but also in those with GH sufficiency after treatment of acromegaly (Group II) demonstrates the significant cardiac impact of acromegaly prior to treatment, and suggests that a longer period of time may be needed to reverse effects of GH excess. The time required to reverse the cardiac morphologic changes that accompany acromegaly is not known. We did not observe correlations between LVMi and time since treatment of acromegaly, but further studies are needed to investigate this potential relationship.

Our finding of increased LVMi in GH sufficient subjects differs from previous studies which demonstrated reduction of LVMi following successful treatment of acromegaly [10,16-19]. In our study, pre-treatment LVMi values were not available for subjects in Groups I and II; we therefore cannot exclude the possibility that the LVMi values of GH sufficient subjects did represent relative decreases from higher pre-treatment baselines.

GH deficiency, in patients without a history of acromegaly, is associated with reduced LVMi [36]. We found that LVMi measurements in adult post-acromegaly GHD subjects were lower than those of post-acromegaly GH sufficient subjects, and clustered toward the lower end of the established normal reference range. LVMi in such patients with a history of GH excess but current GHD had not previously been examined. Our data suggest that reduced LVMi may develop in adult GHD patients. LVM may continue to decline with persistent GH deficiency. 
In our study, in contrast to other reports, differences in diastolic or systolic ventricular function between the groups at rest were not present. There are several potential reasons for this. As shown in previous studies, early functional abnormalities may become evident only under the stress of exercise [46]. Alternatively, some of the changes in diastolic function following biochemical remission of acromegaly, as described in literature, may relate to intravascular volume status and heart rate [16]. In particular, the transmitral diastolic Doppler E/A ratio, while commonly reported in epidemiological studies, is very sensitive to preload in individual patients.

Our study has several limitations. The length of exposure to GH excess, or, following treatment, to GH deficiency is unknown. The symptoms of acromegaly can be insidious, with diagnosis lagging behind onset, and definitive biochemical remission does not reliably follow treatment. In addition, cross-sectional studies such as this cannot determine causality; prospective longitudinal studies are necessary to determine whether echocardiographic measurements change with GH replacement in patients with GH deficiency after cure from acromegaly, and to establish the time course of any changes noted. Finally, as our study population contained no subjects with heart failure, these observations may not apply to the minority of patients with acromegaly who have been diagnosed with cardiomyopathy.

To our knowledge, this is the first published report investigating echocardiographic changes in patients who develop GHD following cure from acromegaly. We found that subjects with post-acromegaly GH deficiency have significantly lower mean LVMi measurements. Many patients with GH sufficiency post-acromegaly, as well as those with active acromegaly, have elevated LVMi measurements. Our results suggest that the effects of growth hormone on the heart are complex. Adults with a history of excess GH exposure followed by GHD represent a unique population, and one in which GH replacement may beneficially impact cardiovascular morbidity and mortality; further studies are warranted to evaluate the impact of GH replacement in these patients, and to better understand the mechanisms responsible for the changes observed and the natural history of these changes.

\section{Acknowledgments}

This work was supported in part by the following grants from the National Institutes of Health: MO1 RR01066, ULI RR0257801, and T32 DK007028, an investigator-initiated research grant from Pfizer and a grant from the Guthart Family Foundation.

\section{References}

1. Rajasoorya C, Holdaway IM, Wrightson P, Scott DJ, Ibbertson HK. Determinants of clinical outcome and survival in acromegaly. Clin Endocrinol (Oxf). 1994; 41:95-102. [PubMed: 8050136]

2. Holdaway IM. Excess mortality in acromegaly. Horm Res. 2007; 68(Suppl 5):166-172. [PubMed: 18174739]

3. Swearingen B, Barker FG 2nd, Katznelson L, et al. Long-term mortality after transsphenoidal surgery and adjunctive therapy for acromegaly. J Clin Endocrinol Metab. 1998; 83:3419-3426. [PubMed: 9768641]

4. Holdaway IM, Rajasoorya RC, Gamble GD. Factors influencing mortality in acromegaly. J Clin Endocrinol Metab. 2004; 89:667-674. [PubMed: 14764779]

5. Clayton RN. Cardiovascular function in acromegaly. Endocr Rev. 2003; 24:272-277. [PubMed: 12788799]

6. Smallridge RC, Rajfer S, Davia J, Schaaf M. Acromegaly and the heart, an echocardiographic study. Am J Med. 1979; 66:22-27. [PubMed: 154293]

7. Rossi L, Thiene G, Caragaro L, Giordano R, Lauro S. Dysrhythmias and sudden death in acromegalic heart disease. A clinicopathologic study. Chest. 1977; 72:495-498. [PubMed: 198185] 
8. Lopez-Velasco R, Escobar-Morreale HF, Vega B, et al. Cardiac involvement in acromegaly: specific myocardiopathy or consequence of systemic hypertension? J Clin Endocrinol Metab. 1997; 82:1047-1053. [PubMed: 9100571]

9. Lombardi G, Galdiero M, Auriemma RS, Pivonello R, Colao A. Acromegaly and the cardiovascular system. Neuroendocrinology. 2006; 83:211-217. [PubMed: 17047385]

10. Lombardi G, Colao A, Marzullo P, Biondi B, Palmieri E, Fazio S. Improvement of left ventricular hypertrophy and arrhythmias after lanreotide-induced GH and IGF-I decrease in acromegaly. A prospective multi-center study. J Endocrinol Invest. 2002; 25:971-976. [PubMed: 12553557]

11. Colao A, Marzullo P, Di Somma C, Lombardi G. Growth hormone and the heart. Clin Endocrinol (Oxf). 2001; 54:137-154. [PubMed: 11207626]

12. Fazio S, Cittadini A, Biondi B, et al. Cardiovascular effects of short-term growth hormone hypersecretion. J Clin Endocrinol Metab. 2000; 85:179-182. [PubMed: 10634384]

13. Frustaci A. Test, Cell death in acromegalic cardiomyopathy. Circulation. 1999; 99:1426-1434. [PubMed: 10086965]

14. Ito H, Hirata Y, Adachi S, et al. Endothelin-1 is an autocrine/paracrine factor in the mechanism of angiotensin II-induced hypertrophy in cultured rat cardiomyocytes. J Clin Invest. 1993; 92:398403. [PubMed: 8326007]

15. Minniti G, Jaffrain-Rea ML, Moroni C, et al. Echocardiographic evidence for a direct effect of GH/IGF-I hypersecretion on cardiac mass and function in young acromegalics. Clin Endocrinol (Oxf). 1998; 49:101-106. [PubMed: 9797853]

16. Pivonello R, Galderisi M, Auriemma RS, et al. Treatment with growth hormone receptor antagonist in acromegaly: effect on cardiac structure and performance. J Clin Endocrinol Metab. 2007; 92:476-482. [PubMed: 17105844]

17. Maison P, Tropeano AI, Macquin-Mavier I, Giustina A, Chanson P. Impact of somatostatin analogs on the heart in acromegaly: ametaanalysis. J Clin Endocrinol Metab. 2007; 92:1743-1747. [PubMed: 17311857]

18. Colao A, Pivonello R, Galderisi M, et al. Impact of treating acromegaly first with surgery or somatostatin analogs on cardiomyopathy. J Clin Endocrinol Metab. 2008; 93:2639-2646. [PubMed: 18445662]

19. DeMarinis L, Bianchi A, Mazziotti G, et al. The long-term cardiovascular outcome of different GH-lowering treatments in acromegaly. Pituitary. 2008; 11:13-20. [PubMed: 17987389]

20. Rosen T, Bengtsson BA. Premature mortality due to cardiovascular disease in hypopituitarism. Lancet. 1990; 336:285-288. [PubMed: 1973979]

21. Beauregard C, Utz A, Schaub AE, et al. Growth hormone (GH) decreases visceral fat and improves cardiovascular risk (CV) markers in women with hypopituitarism: a randomized, placebocontrolled study. J Clin Endocrinol Metab. 2008; 93:2063-2071. [PubMed: 18381581]

22. Oliveira JL, Aguiar-Oliveira MH, D’Oliveira A Jr, et al. Congenital growth hormone (GH) deficiency and atherosclerosis: effects of GH replacement in GH-naive adults. J Clin Endocrinol Metab. 2007; 92:4664-4670. [PubMed: 17911170]

23. Colao A, Di Somma C, Spiezia S, et al. The natural history of partial growth hormone deficiency in adults: a prospective study on the cardiovascular risk and atherosclerosis. J Clin Endocrinol Metab. 2006; 91:2191-2200. [PubMed: 16537686]

24. Cuneo RC, Salomon F, McGauley GA, Sonksen PH. The growth hormone deficiency syndrome in adults. Clin Endocrinol (Oxf). 1992; 37:387-397. [PubMed: 1486686]

25. De Boer H, Blok GJ, Voerman HJ, De Vries PM, van der Veen EA. Body composition in adult growth hormone-deficient men, assessed by anthropometry and bioimpedance analysis. J Clin Endocrinol Metab. 1992; 75:833-837. [PubMed: 1517374]

26. Binnerts A, Deurenberg P, Swart GR, Wilson JH, Lamberts SW. Body composition in growth hormone-deficient adults. Am J Clin Nutr. 1992; 55:918-923. [PubMed: 1570798]

27. Weaver JU, Monson JP, Noonan K, et al. The effect of low dose recombinant human growth hormone replacement on regional fat distribution, insulin sensitivity, and cardiovascular risk factors in hypopituitary adults. J Clin Endocrinol Metab. 1995; 8:153-159. [PubMed: 7829604] 
28. Gomez JM, Sahun M, Vila R, et al. Peripheral fibrinolytic markers, soluble adhesion molecules, inflammatory cytokines and endothelial function in hypopituitary adults with growth hormone deficiency. Clin Endocrinol (Oxf). 2006; 64:632-639. [PubMed: 16712664]

29. Colao A, Di Somma C, Cuocolo A, et al. Does a gender-related effect of growth hormone (GH) replacement exist on cardiovascular risk factors, cardiac morphology, and performance and atherosclerosis? Results of a two-year open, prospective study in young adult men and women with severe GH deficiency. J Clin Endocrinol Metab. 2005; 90:5146-5155. [PubMed: 15985481]

30. Rosen T, Eden S, Larson G, Wilhelmsen L, Bengtsson BA. Cardiovascular risk factors in adult patients with growth hormone deficiency. Acta Endocrinol (Copenh). 1993; 129:195-200. [PubMed: 8212983]

31. Barreto-Filho JA, Alcantara MR, Salvatori R, et al. Familial isolated growth hormone deficiency is associated with increased systolic blood pressure, central obesity, and dyslipidemia. J Clin Endocrinol Metab. 2002; 87:2018-2023. [PubMed: 11994335]

32. Cuneo RC, Salomon F, Watts GF, Hesp R, Sonksen PH. Growth hormone treatment improves serum lipids and lipoproteins in adults with growth hormone deficiency. Metabolism. 1993; 42:1519-1523. [PubMed: 8246764]

33. Devin JK, Blevins LS Jr, Verity DK, et al. Markedly impaired fibrinolytic balance contributes to cardiovascular risk in adults with growth hormone deficiency. J Clin Endocrinol Metab. 2007; 92:3633-3639. [PubMed: 17579195]

34. Shahi M, Beshyah SA, Hackett D, Sharp PS, Johnston DG, Foale RA. Myocardial dysfunction in treated adult hypopituitarism: a possible explanation for increased cardiovascular mortality. $\mathrm{Br}$ Heart J. 1992; 67:92-96. [PubMed: 1739534]

35. Longobardi S, Cuocolo A, Merola B, et al. Left ventricular function in young adults with childhood and adulthood onset growth hormone deficiency. Clin Endocrinol (Oxf). 1998; 48:137143. [PubMed: 9579223]

36. Colao A, di Somma C, Cuocolo A, et al. Improved cardiovascular risk factors and cardiac performance after 12 months of growth hormone $(\mathrm{GH})$ replacement in young adult patients with GH deficiency. J Clin Endocrinol Metab. 2001; 86:1874-1881. [PubMed: 11344175]

37. Merola B, Cittadini A, Colao A, et al. Cardiac structural and functional abnormalities in adult patients with growth hormone deficiency. J Clin Endocrinol Metab. 1993; 77:1658-1661. [PubMed: 8263155]

38. Valcavi R, Gaddi O, Zini M, Iavicoli M, Mellino U, Portioli I. Cardiac performance and mass in adults with hypopituitarism: effects of one year of growth hormone treatment. J Clin Endocrinol Metab. 1995; 80:659-666. [PubMed: 7852533]

39. Biller BM, Samuels MH, Zagar A, et al. Sensitivity and specificity of six tests for the diagnosis of adult GH deficiency. J Clin Endocrinol Metab. 2002; 87:2067-2079. [PubMed: 11994342]

40. Hartman ML, Crowe BJ, Biller BM, Ho KK, Clemmons DR, Chipman JJ. Which patients do not require a GH stimulation test for the diagnosis of adult GH deficiency? J Clin Endocrinol Metab. 2002; 87:477-485. [PubMed: 11836272]

41. Wexler T, Gunnell L, Omer Z, et al. Growth hormone deficiency is associated with decreased quality of life in patients with prior acromegaly. J Clin Endocrinol Metab. 2009; 94:2471-2477. [PubMed: 19366847]

42. Levy D, Savage DD, Garrison RJ, Anderson KM, Kannel WB, Castelli WP. Echocardiographic criteria for left ventricular hypertrophy: the Framingham Heart Study. Am J Cardiol. 1987; 59:956-960. [PubMed: 2952002]

43. Devereux RB, Reichek N. Echocardiographic determination of left ventricular mass in man. Anatomic validation of the method. Circulation. 1977; 55:613-618. [PubMed: 138494]

44. Nagueh SF, Appleton CP, Gillebert TC, et al. Recommendations for the evaluation of left ventricular diastolic function by echocardiography. J Am Soc Echocardiogr. 2009; 22:107-133. [PubMed: 19187853]

45. Verma A, Meris A, Skali H, et al. Prognostic implications of left ventricular mass and geometry following myocardial infarction: the VALIANT (VALsartan In Acute myocardial iNfarcTion) Echocardiographic Study. JACC Cardiovasc Imaging. 2008; 1:582-591. [PubMed: 19356485] 
46. Colao AA. The GH/IGF axis and the cardiovascular system: clinical implications. Clin Endocrinol (Oxf). 2008; 69:347-358. [PubMed: 18462260] 


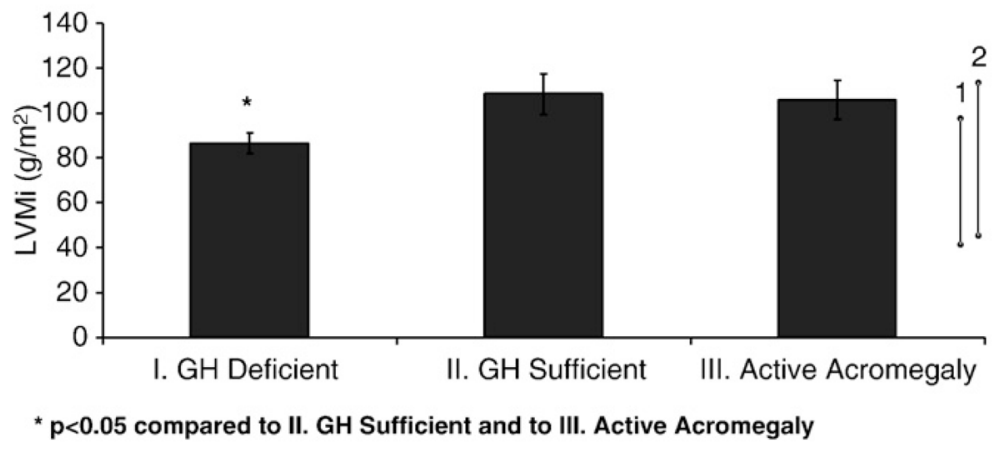

Fig. 1.

LVMi is lower in patients with GH deficiency post-acromegaly. Left ventricular mass (indexed to body surface area) was lower in patients who developed GH deficiency after acromegaly (I), than in either patients with active acromegaly (III) $(p=0.02)$ or those who achieved GH sufficiency after cure (II) $(p=0.049)$. There was no difference between patients with active acromegaly and post-acromegaly GH sufficient patients. Bars indicate normal LVMi levels for women [1] and men [2]. * $p<0.05$ compared to (II) GH sufficient and to (III) active acromegaly. 
Table 1

Clinical characteristics of subject population ${ }^{a}$.

\begin{tabular}{|c|c|c|c|}
\hline & GH deficient $n=15$ & GH sufficient $n=8$ & Active acromegaly $n=11$ \\
\hline Age (year) & $4.2 \pm 1.4$ & $4.5 \pm 1.5$ & $4.9 \pm 1.0$ \\
\hline Gender $(\mathrm{M} / \mathrm{F})$ & $8 \mathrm{M} / 7 \mathrm{~F}$ & $2 \mathrm{M} / 6 \mathrm{~F}$ & $5 \mathrm{M} / 6 \mathrm{~F}$ \\
\hline IGF-I (ng/ml) & $9.8 \pm 4.8^{* * * *}$ & $11.2 \pm 3.8^{* * *}$ & $59.9 \pm 21, .1 * * *$ \\
\hline Peak GH level (ng/ml) & $2.8 \pm 0.4^{* *}$ & $30.1 \pm 9.1 *$ & N/A \\
\hline BMI $\left(\mathrm{kg} / \mathrm{m}^{2}\right)$ & $3.5 \pm 6.7$ & $3.0 \pm 8.4$ & $2.5 \pm 8.1$ \\
\hline Waist circumference $(\mathrm{cm})$ & $10.7 \pm 1.2$ & $9.1 \pm 1.8$ & $9.4 \pm 2.1$ \\
\hline Waist/hip ratio & $0.91 \pm 0.07^{* *}$ & $0.84 \pm 0.06^{*}$ & $0.87 \pm 0.0$ \\
\hline History of surgery $(\mathrm{n}, \%)$ & $12(80 \%)^{* * *}$ & $8(100 \%)^{* * * *}$ & $4(37 \%)^{* * * *}$ \\
\hline Time since surgery (mos) & $9.6 \pm 5.1$ & $93 \pm 7.1$ & $3.6 \pm 4.1$ \\
\hline History of radiotherapy $(n, \%)$ & $9(60 \%)^{* * *}$ & $3(38 \%)^{* * * *}$ & $0^{* * * *}$ \\
\hline Time since Radiotherapy & $19.6 \pm 15.4$ & $12.3 \pm 12.9$ & N/A \\
\hline Duration of disease (mos) & $13.3 \pm 8.7^{* * *}$ & $13.2 \pm 11.6^{* * *}$ & $6.0 \pm 8.4^{* * *}$ \\
\hline $\operatorname{ACTH}$ deficiency $(n, \%)^{* * *}$ & $6(40 \%)$ & $1(13 \%)$ & $0 *$ \\
\hline TSH deficiency (n,\%) & $9(60 \%)^{* * *}$ & $3(38 \%)^{* * *}$ & $0^{* * * *}$ \\
\hline Free $\mathrm{T} 4(\mathrm{ng} / \mathrm{dL})$ & $1.26 \pm 0.2$ & $1.28 \pm 0.1$ & $1.32 \pm 0.2$ \\
\hline Male hypogonadism $(n, \%)$ & $7(88 \%)$ & $1(50 \%)$ & $2(40 \%)$ \\
\hline Primary hypogonadisn (female) $(n, \%)$ & $2(29 \%)$ & $3(50 \%)$ & $3(50 \%)$ \\
\hline Secondary hypogonadism (female) $(n, \%)$ & $4(57 \%)^{* * *}$ & $1(17 \%)$ & 0 \\
\hline Current Tobacco Use (no.\%) & $1(7 \%)$ & 0 & $1(9 \%)$ \\
\hline Systolic/diastolic blood pressure & $117 \pm 1 / 174 \pm 8$ & $120 \pm 1 / 174 \pm 9$ & $124 \pm 1 / 178 \pm 1$ \\
\hline Mean arterial blood pressure $(\mathrm{mmHg})$ & $88 \pm 8$ & $90 \pm 1$ & $93 \pm 1$ \\
\hline \multicolumn{4}{|c|}{$*^{*}<0.05$; significantly different from GHD group. } \\
\hline \multicolumn{4}{|c|}{$p<0.05$; significantly different from GHS group. } \\
\hline${ }^{* * * *}<0.05$; significantly different from acti & acromegaly group. & & \\
\hline
\end{tabular}




\section{Table 2}

LVMi distribution among subject groups.

\begin{tabular}{lcl}
\hline & Normal LVMi $^{a}$ & Elevated LVMi \\
\hline GHD $n=14$ & $14(100 \%)$ & 0 \\
GHS $n=8$ & $3(38 \%)$ & $5(62 \%)$ \\
AA $3 n=11$ & $6(55 \%)$ & $5(45 \%)$ \\
\hline
\end{tabular}

${ }^{a}$ LVMi not above upper limit of established gender-specific reference range; of note, there is no officially defined lower limit of normal 


\section{Table 3}

Diastolic function in subjects groups.

\begin{tabular}{lrll}
\hline & Normal & Mild dysfunction (impaired relaxation) & Moderate dysfunction (pseudonormal) \\
\hline GHD $n=15$ & $10(66 \%)$ & $4(27 \%)$ & $1(7 \%)$ \\
GHS $n=8$ & $5(62 \%)$ & $3(38 \%)$ & 0 \\
AA $n=11$ & $8(72 \%)$ & $2(18 \%)$ & $1(10 \%)$ \\
\hline
\end{tabular}

